\title{
Team Teaching Load using Linear Programming
}

\section{Syadatul Syaeda Mat Saleh ${ }^{1 *}$, Nurul Husna Jamian ${ }^{2}$, Najihan Awang@ Ali ${ }^{3}$}

\author{
${ }^{1,2,3}$ Faculty of Computer and Mathematical Sciences (FSKM), \\ Universiti Teknologi MARA, Perak Branch, Tapah Campus, 35400 \\ Tapah Road, Perak, Malaysia
}

Corresponding author: *syada326@uitm.edu.my

Received Date: 13 September 2019

Accepted Date: 24 September 2019

\begin{abstract}
Assignment of teaching loads refers to the allocation of teaching hours among academic staff. It will be the ideal way to assign the right courses to the right staff based on their expertise, preference and experience. The common practice in this department to allocate the teaching load is done manually through trial-and-error using Microsoft Excel which is inefficient and time consuming. Moreover, the manual allocation may lead to bias judgement and get unfavourable courses among academic staff. Thus, this study aims to propose a teaching load allocation model which able to optimize the teaching quality. A primary data has been collected using google form among 25 lecturers with 13 courses considered. Then, a linear programming model was applied based on department policies as constraints in order to find an optimal solution. A feasible solution will be solved using LINGO optimization software and the model serves as a best tool to assist head of department to allocate teaching loads. It found that the model proposed is suitable to be employed for teaching load allocation in this department .
\end{abstract}

Keywords: assignment problem, linear programming, team teaching 


\section{INTRODUCTION}

Assigning teaching workload is one of the biggest concern as it is very important to improve the teaching quality (Xiaobo et al., 2014). Assigning can be defined as a process of the distribution of tasks or work to each staff. In education management, one of the major task is assigning teaching workload which carried out in all teaching institution in every semester. The course assignment is an important task for the administrative team that need to make sure all the course demands are met.

Generating teaching load for a department is a very challenging and time consuming task due to diverse demands, faculty preference, availability of the staff members, number of codes and number of groups. All the courses must assigned to the faculty members who can teach the course well with respective expertise.

Before the semester start, the administrative team needs to forecast the demand for each course and determine the required number of students enroll for each course. In addition, Xiaobo et al. (2014) and Shin and Jung (2013) studied preparation for teaching course has been well recognized as a major contributing factor to get the teaching quality.

There are a lot of studies that had been done about the problem of assigning courses to the lecturers or to the time slot. A study by MA Nang Laik and Sen Prabir (2017), it proposed an innovative method to solve the faculty assignment for the university using two-steps approach. By using this approach, they able to reduce the number of variables and errors in runtime. Then, Breslaw (1976) studied a linear programming solution to the faculty assignment problem by using optimization methods in the solution. Another study by Nordin (2006) performed the feasibility in assigning lecturers to courses under various policies or conditions using the methods of operations research that has been done using LINGO software. Gunawan et al. (2008) carried out the scheduling problems that exist in the institution in Indonesia. Their research involved the problem of assigning teachers to the courses and the times at the university level. The proposed algorithm had produced a better solution instead of manually distribution by the institutions.

Badri et al. (1996) proposed a two-stage multi-objective scheduling model for faculty-course-time assignments by using faculty course preference and time slot as objectives of the research. Bakir et al. (2008) stated that to organize the courses code by assigning the 
lecturers according to periods and availability of the classrooms is very difficult assignment scheduling problem. In their study, the zero-one integer programming model has been developed in order to minimize the dissatisfaction of lecturers and students. Fairuz et al. (2016) reported that optimization model using linear programming is most suitable to optimize and organize teaching load allocation at mathematics department.

Preparations for the workload allocation could lead to irregularities in the total number of lecturers teaching hours in a week, the course code and the number of groups should be teach. These irregularities will cause dissatisfaction among lecturers and also assigning of courses to the unexperienced lecturers will occur. It is due to manually allocation through trial-and-error using Microsoft Excel which is inefficient and time consuming. Moreover, the manual allocation may lead to bias judgement, get unfavourable courses and lack of standardization on the total hours per week for each academic staff (Mat Saleh, 2011). Therefore, this study aims to propose a teaching load allocation model which able to optimize the teaching quality.

\section{DATA SOURCES}

The teaching loads of lecturers must be prepared by the head of department under his or her supervision before the semester begins. Several factors need to be considered before develop the assignment tables, such as the number of existing lecturers, the existing courses and the total number of groups for each course based on number of students enrolled for a course in every semester.

In every semester, the head of department has to decide how should the courses offered be the best allocated amongst its staff so as to optimise some measure of output criteria as chosen or set by the head of department or the education authority.Usually, the assignment is done manually based on course preferences responded by each lecturer. However, teaching preferences sometimes are not taken into consideration due to various constraints appeared.

Since each lecturers have different expertise, preference and experience toward a particular course, a survey was conducted to obtain the required information using google form and distributes to all the academic staff in the department. A primary data has been collected among 25 lecturers with number of group listed for each 13 courses 
considered. Contact hours per week for each course has different allocation. The contact hours and the number of groups are shown in Table 1 below.

Table 1: Contact Hours and Number of Groups

\begin{tabular}{|c|c|c|}
\hline Subjects & $\begin{array}{c}\text { Contact Hours } \\
\text { Per Week }\end{array}$ & $\begin{array}{c}\text { Number of } \\
\text { Groups }\end{array}$ \\
\hline XXX123 & 4 & 8 \\
\hline XXX133 & 4 & 24 \\
\hline XXX112 & 4 & 19 \\
\hline XXX183 & 4 & 14 \\
\hline XXX233 & 4 & 2 \\
\hline XXX222 & 4 & 2 \\
\hline XXX238 & 4 & 28 \\
\hline XXX210 & 4 & 6 \\
\hline XXX263 & 4 & 7 \\
\hline XXX272 & 5 & 2 \\
\hline XXX300 & 4 & 2 \\
\hline XXX421 & 4 & 2 \\
\hline XXX423 & 4 & 4 \\
\hline
\end{tabular}

The lecturers must fill in the google form based on preference weights from 0 to 3 . The description of preference weights as follows:

Weight 0 : The lecturers does not prefer to teach that course and has no experience teaching of it.

Weight 1 : The lecturers does not prefer to teach that course but has experience teaching of it.

Weight 2 : The lecturers prefer to teach that course but has no experience teaching of it.

Weight 3 : The lecturers prefer to teach that course and has experience teaching of it.

Based on the preference weights, the teaching allocation aims to allocate the lecturer to the most suitable courses, based on their expertise, preference and experience. The dataset recorded as shown in the Table 2 below. 
Table 2: Preference Weights

\begin{tabular}{|c|c|c|c|c|c|c|c|c|c|c|c|c|c|}
\hline \multirow[b]{2}{*}{ LECTURERS } & \multicolumn{13}{|c|}{ COURSES } \\
\hline & XXX423 & XXX123 & XXX133 & XXX112 & XXX183 & XXX233 & XXX222 & XXX238 & XXX210 & XXX263 & XXX272 & XXX300 & XXX421 \\
\hline L1 & 1 & 1 & 1 & 1 & 3 & 3 & 3 & 3 & 0 & 0 & 0 & 2 & 0 \\
\hline L2 & 1 & 3 & 3 & 1 & 3 & 0 & 0 & 3 & 0 & 0 & 0 & 0 & 0 \\
\hline L3 & 0 & 0 & 0 & 0 & 1 & 0 & 0 & 3 & 3 & 0 & 0 & 0 & 0 \\
\hline L4 & 3 & 0 & 3 & 0 & 3 & 0 & 0 & 2 & 0 & 3 & 2 & 1 & 3 \\
\hline L5 & 0 & 0 & 3 & 0 & 3 & 3 & 3 & 3 & 3 & 2 & 1 & 2 & 2 \\
\hline L6 & 0 & 0 & 0 & 0 & 1 & 1 & 0 & 3 & 0 & 1 & 0 & 1 & 1 \\
\hline L7 & 1 & 3 & 1 & 3 & 3 & 3 & 2 & 1 & 2 & 3 & 2 & 2 & 2 \\
\hline L8 & 3 & 0 & 1 & 0 & 3 & 3 & 3 & 2 & 1 & 1 & 0 & 3 & 3 \\
\hline L9 & 1 & 0 & 1 & 3 & 3 & 3 & 0 & 0 & 0 & 3 & 2 & 0 & 2 \\
\hline L10 & 1 & 0 & 3 & 3 & 0 & 0 & 0 & 0 & 0 & 0 & 0 & 0 & 0 \\
\hline L11 & 1 & 0 & 1 & 3 & 3 & 3 & 0 & 1 & 0 & 3 & 0 & 0 & 2 \\
\hline L12 & 3 & 1 & 1 & 3 & 3 & 1 & 1 & 1 & 1 & 1 & 1 & 1 & 1 \\
\hline L13 & 0 & 2 & 3 & 3 & 3 & 2 & 3 & 3 & 0 & 3 & 0 & 0 & 2 \\
\hline L14 & 0 & 0 & 0 & 1 & 1 & 1 & 0 & 0 & 0 & 3 & 0 & 3 & 0 \\
\hline L15 & 1 & 0 & 3 & 3 & 3 & 2 & 1 & 0 & 0 & 0 & 0 & 0 & 3 \\
\hline L16 & 0 & 0 & 3 & 1 & 3 & 2 & 1 & 3 & 1 & 3 & 0 & 0 & 0 \\
\hline L17 & 0 & 0 & 0 & 0 & 3 & 3 & 3 & 3 & 0 & 0 & 3 & 3 & 3 \\
\hline L18 & 1 & 1 & 1 & 3 & 0 & 1 & 1 & 1 & 1 & 3 & 3 & 0 & 0 \\
\hline L19 & 1 & 1 & 1 & 1 & 3 & 3 & 3 & 0 & 3 & 0 & 0 & 0 & 3 \\
\hline L20 & 1 & 0 & 3 & 1 & 3 & 3 & 0 & 3 & 0 & 2 & 0 & 2 & 2 \\
\hline L21 & 0 & 1 & 1 & 3 & 3 & 1 & 0 & 0 & 0 & 1 & 0 & 0 & 3 \\
\hline L22 & 1 & 0 & 3 & 0 & 3 & 0 & 0 & 3 & 0 & 1 & 0 & 3 & 0 \\
\hline L23 & 1 & 2 & 3 & 1 & 3 & 3 & 2 & 3 & 2 & 3 & 0 & 2 & 2 \\
\hline L24 & 1 & 0 & 3 & 1 & 3 & 1 & 0 & 3 & 0 & 3 & 0 & 3 & 2 \\
\hline L25 & 0 & 1 & 3 & 3 & 3 & 2 & 2 & 2 & 2 & 2 & 1 & 2 & 2 \\
\hline
\end{tabular}

\section{LINEAR PROGRAMMING OPTIMIZATION MODEL}

A linear programming model was applied based on department policies as constraints in order to find an optimal solution. A feasible solution will be solved using LINGO optimization software and the model serves as a best tool to assist head of department to allocate teaching loads.In this department, there are few policies that have to be followed as shown in Table 3.

Table 3: Policies

\begin{tabular}{|c|c|c|}
\hline & Minimum & Maximum \\
\hline $\begin{array}{c}\text { Contact hours per week for each } \\
\text { lecturer }\end{array}$ & 16 & 20 \\
\hline Number of classes & 4 & 5 \\
\hline
\end{tabular}

To address the teaching workload allocation problem, we develop a mathematical optimization model. The notations formulation used is listed below. 
$I \quad:$ the index of all courses, $i$

$J: \quad$ the index of all lecturers, $j$

$X_{i j}$ : the number of teaching hours for course $i$ teachingby the lecturer $j$

$W_{i j} \quad$ : the teaching preference weight for course $i$, lecturer $j$

$C_{i}$ : the number of classes for course $i$

$t_{i} \quad:$ the contact hour for course $i$

$K S_{j}^{m i n}$ :the minimum number of teaching hours for lecturer $j$ of the week

$K S_{j}^{\max }$ : the maximum number of teaching hours for lecturer $j$ of the week

$n_{j}^{\text {min }} \quad$ : the minimum number of classes for lecturer $j$

$n_{j}^{\max }$ : the maximum number of classes for lecturer $j$

The linear programming model can be formulated as follows.

$$
\max \sum_{i \in I} \sum_{j \in J} W_{i j} X_{i j}
$$

subject to

$$
\begin{aligned}
& \sum_{j \in J} X N_{i j}, \text { for } i \in I \\
& t_{j}^{m i n} \leq \sum_{i \in I} t_{i} X_{i j} \leq t_{j}^{m a x}, \quad \text { for } j \in J \\
& n_{j}^{m i n} \leq \sum_{i=1}^{m} X_{i j} \leq n_{j}^{m a x}, \quad \text { for } j \in J \\
& 0 \leq X_{i j} \leq 2, \text { for } i \in I, j \in J
\end{aligned}
$$

The objective function (1) maximizes the total number of courses that are taught by the most suitable lecturers according to their preference weights. Equation (2) impose that the number of classes for each course. Equation (3) refers to the contact hours per week for each lecturer. Equation (4) impose that a number of classes that lecturer 
should teach and equation (5) allocates that at most two classes of the same course.

\section{RESULTS AND DISCUSSIONS}

The optimization model can be efficently solved using LINGO unlimited software and a feasible solution was found. The optimization teaching load allocation is shown in Table 4. It found that all the lecturer are assigned between 16 and 20 contact hours per week and they are allocated between 4 to 5 number of groups as well, as stipulated in department policies. This results revealed that most of the courses efficiently allocated to every lecturer based on their preferences weights. For example, L1, he/she assigned 2 groups of XXX183 (Weight 3), 1 group XXX222(Weight 3) and 2 groups of XXX238 (Weight 3). Meanwhile for L7, he/she assigned 2 groups of XXX123 (Weight 3), 2 groups XXX112(Weight 3) and 1 group of XXX210 (Weight 1).

Table 4: Optimized teaching load allocations

\begin{tabular}{|c|c|c|c|c|c|c|c|c|c|c|c|c|c|c|c|}
\hline \multirow[b]{2}{*}{ LECTURERS } & \multicolumn{13}{|c|}{ COURSES } & \multirow[b]{2}{*}{\begin{tabular}{|c|} 
NUMBER \\
OF \\
GROUPS \\
FOR EACH \\
LECTURER \\
\end{tabular}} & \multirow[b]{2}{*}{$\mid \begin{array}{c}\text { CONTACT } \\
\text { HOURS } \\
\text { PER WEEK }\end{array}$} \\
\hline & XXX423 & XXX123 & XXX133 & $x \times x 11$ & XXX183 & XXX233 & XXX222 & $x \times x 238$ & xxx210 & XXX263 & XXX272 & $x \times x 300$ & $x x \times 421$ & & \\
\hline L1 & & & & & 2 & & 1 & 2 & & & & & & 5 & 20 \\
\hline L2 & & 2 & 2 & & & & & 1 & & & & & & 5 & 20 \\
\hline L3 & & & & & & & & 2 & 2 & & & & & 4 & 16 \\
\hline$L 4$ & & & 2 & & 1 & & & 2 & & & & & & 5 & 20 \\
\hline 55 & & & 2 & & & & & 2 & 1 & & & & & 5 & 20 \\
\hline L6 & & 2 & & & & & & 2 & & & & & & 4 & 16 \\
\hline L7 & & 2 & & 2 & & & & & 1 & & & & & 5 & 20 \\
\hline L8 & 2 & & & & 1 & & & 2 & & & & & & 5 & 20 \\
\hline 59 & & & & 2 & 2 & & & & & 1 & & & & 5 & 20 \\
\hline L10 & & & 2 & 2 & & & & & & & & & & 4 & 16 \\
\hline L11 & & & & 2 & 1 & & & & & 1 & & & & 4 & 16 \\
\hline L12 & 2 & & & 2 & 1 & & & & & & & & & 5 & 20 \\
\hline L13 & & & 2 & 1 & & & & 2 & & & & & & 5 & 20 \\
\hline L14 & & & & & & & & & & 2 & & 2 & & 4 & 16 \\
\hline L15 & & & 2 & 2 & & & & & & & & & 1 & 5 & 20 \\
\hline L16 & & & 2 & & & & & 2 & & 1 & & & & 5 & 20 \\
\hline L17 & & & & & & & 1 & 2 & & & 2 & & & 5 & 20 \\
\hline L18 & & 1 & & 2 & & & & & & 2 & & & & 5 & 20 \\
\hline L19 & & & & & 2 & 1 & & & 2 & & & & & 5 & 20 \\
\hline L20 & & & 2 & & & 1 & & 2 & & & & & & 5 & 20 \\
\hline L21 & & & & 2 & 2 & & & & & & & & 1 & 5 & 20 \\
\hline L22 & & & 2 & & 1 & & & 2 & & & & & & 5 & 20 \\
\hline L23 & & 1 & 2 & & & & & 2 & & & & & & 5 & 20 \\
\hline L24 & & & 2 & & 1 & & & 2 & & & & & & 5 & 20 \\
\hline L25 & & & 2 & 2 & & & & 1 & & & & & & 5 & 20 \\
\hline
\end{tabular}




\section{CONCLUSION}

As conclusion, the optimization model used in this study is very suitable and help in improving the teaching quality by allocating the most appropriate lecturers to teach the course. It is hoped that this model can widely apply for other academic department where it also benefits the head of departments in timetable arrangements. For further improvement, the mathematical model is suggested to consider many more contraints such as for lecturers who hold a post in administration.

\section{REFERENCES}

Badri, M. A., Davis, D. L., Davis, D. F.\& Hollingsworth, J. (1998). A MultiObjective Course Scheduling Model: Combining Faculty Preference For Courses and Times. Journal of Computer Operations Research,25(4), 303-316.

Bakir, M. A.\&Aksop, C. (2008). A 0-1 Integer Programming Approach To A University Timetabling Problem. Hacettepe Journal of Mathematics and Statistics, 37(1), 41-55.

Breslaw J. A. (1976). A Linear Programming Solution to the Faculty Assignment Problem. Socio-Economic Planning Sciences, 10(6), 227230. https://doi.org/10.1016/0038-0121(76)90008-2.

Gunawan, A., Ng, K. M.,\& Ong, H. L. (2008). A Genetic Algorithm for the Teacher Assignment Problem for a University in Indonesia. Journal of Information and Management Sciences,19 (1), 1-16.

Mat Saleh S. S. \& Ismail W. R. (2011). Pengoptimuman Masalah Umpukkan Pengajaran Berkumpulan Fakulti Menggunakan Kaedah Pengaturcaraan Integer 0-1. Proceeding in International Seminar on the Application of Science \& Mathematics 2011.

Nang L. MA \& Prabir, S. (2017). Faculty Assignment and Timetabling Using Optimisation. International Journal of Computer Science and Information Security (IJCSIS), 15, 29-35.

Nordin Hj. Mohamad. (2006). A Zero-One Integer Programming Approach to the Assignments of Lecturers to Courses. Kuala Lumpur: Penerbit UM.

Qu, X., Wang, S., Easa, S., \& Liu, Z. (2014). Teaching Load Allocation in a Teaching Unit: Optimizing Equity And Quality. In Proceedings AAEE2014: Engineering the Knowledge Economy: Collaboration, Engagement \& Employability.

Shin, J.C. \& Jung, J., (2013). Academics Job Satisfaction and Job Stress Across Countries in the Changing Academic Environments. Higher Education. https://doi.org/10.1007/s10734-013-9668-y.

Shohaimay F., Dasman A. \& Suparlan A. (2016). Teaching Load Allocation using Linear Programming: A Case Study in Mathematics Department. Business Management and Computing Research Colloqium (BMCRC2016). 